\title{
Smart Grid Technology and Renewable Energy Integration in the Ghanaian Grid System
}

\author{
Kingsley Akom ${ }^{1}$, Bernard Adjei-Frimpong ${ }^{2}$, Kwadwo Ntiamoah-Sarpong ${ }^{3}$ \\ ${ }^{1}$ Kumasi Polytechnic, Department of Electrical Engineering, P.O. Box 854, Ghana \\ ${ }^{2}$ Department of Electrical Engineering, Kumasi Polytechnic, P.O. Box 854, Ghana \\ ${ }^{3}$ Kumasi Polytechnic, Department of electrical Engineering, P.O. Box 854, Ghana
}

\begin{abstract}
Ghana's electricity system in the recent years has suffered many setbacks resulting in almost five years of load shedding. The electricity situation in Ghana can be described as epileptic with no sign in view of improvement. The power situation has affected the manufacturing, service and residential sectors of the economy which in turn affects the country's economic growth. Even with the recent reforms in the energy sector where power was separated from the Energy Ministry to stand as Power Ministry, a larger population does not have access to reliable supply of electricity. The epileptic condition of the power sector can be attributed to the inadequate and inefficient power plants, poor transmission and distribution facilities, and outdated metering system used by electricity consumers. This paper attempts to present the way forward for the Ghanaian poor electricity situation by reviewing the power sector as a whole and the renewable energy potentials. We identified the problems in the national grid and then proposed a smart grid model for the Ghanaian power sector which will include renewable energy source. We believe that the content of this review paper will solve the poor condition of the power sector in Ghana and also enable the proper integration of smart grid technology into the national grid.
\end{abstract}

Keywords: Power plant, smart grid, transmission, electricity.

\section{Introduction}

Electricity is an important facet of any nation's development. In Ghana, electricity is the pillar of its growth and development with roles in the nation's production of goods and services in the industrial sector as well as agriculture, health and education [1]. Ghana, a country known as "the gate way to Africa" is blessed with an abundant amount of fossil fuel and renewable energy resources, but the country is battling with an acute epileptic power situation. According to the World Bank data; about $68.3 \%$ of Ghanaians have access to electricity [2].

Ghana's poor energy situation results from the national grid network with problems ranging from inefficient power plants which are few in numbers to lack of renewables to support peak load, physical deterioration of the long transmission lines to distribution facilities which are inadequately maintained, lack of communication facilities, illegal electricity connections and outdated meters used by the consumers [1]. However, this paper tends to address the research question: what is the way forward for the Ghana's poor electricity situation? In order to solve the above research question, the paper reviews the current electricity sector in Ghana and the concept of smart grid technology. Furthermore, we suggest a future direction on the integration of smart grid into the Ghanaian electricity grid network in conjunction with renewable energy. This study therefore will among others propose a public relation model which aims at educating and sensitising the general public on the efficient use of domestic power and also ensure that, information on energy management tool is right at the door-step of every consumer.

\section{Objective}

The main objective of the paper is to explore Smart Grid Technology and Renewable Energy Integration in the Ghanaian Grid System

\subsection{Sub-objectives}

The paper will further explore: the overview of the power sector where we reviewed the history of the power sector and its various sectors and the current electricity situation in Ghana and renewables. The second section introduces the smart grid technology and advanced metering infrastructure, while the third section discusses about the integration of smart gird technology into the Ghanaian grid network and the various technological upgrades required making the smart grid system in Ghana possible. The forth section examined factors that may affect smart grid integration in Ghana. And the fifth section discussed benefits of smart grid technology. We believe that this paper will contribute immensely to the possibility of smart grid and renewable integration into the Ghanaian electricity grid.

\section{Overview of the Ghanaian Power Sector}

\subsection{History}

In Ghana, the Volta River Authority (VRA) was established in 1961 to provide electricity to provide electricity for Ghana's economic development. The VRA operates a total installed electricity of about $1740 \mathrm{MW}$ made up of $1180 \mathrm{MW}$ of hydro and $660 \mathrm{MW}$ of thermal energies.

In addition to these, there is a $126 \mathrm{MW}$ from the Tema Thermal 1 Power Plant at Tema, which is currently operated 


\section{International Journal of Science and Research (IJSR) \\ ISSN (Online): 2319-7064 \\ Index Copernicus Value (2013): 6.14 | Impact Factor (2015): 6.391}

only during contingencies. According to the 2002 census report, only $43 \%$ of the population had access to electricity supply. Over $80 \%$ of the domestic electricity supply is consumed in the cities and urban settlements. As at 1995, Ghana had excess electricity which led to the export of electricity by the VRA to Campagne Ivorien d'Electricite (CIE) of Cote d'Ivoire and Communuate Electrique du Benin (CEB) of Togo and Benin under a power supply contract. However, this has dwindled drastically over the years due to increasing local demand for power and inadequate expansion of the generation capacity. Power supply to CIE ceased after 1995. VRA now exports power only to CEB of Togo and Benin and imports a maximum of $250 \mathrm{MW}$ from Cote d'Ivoire during contingencies. Inferring from the above is the need for an effective energy saving management policy to arrest the situation [3].

Ghana's electricity generation has traditionally been dominated by hydro assets; however, in recent years hydro has been complemented by fossil fuel generation to meet rapidly growing demand. Total installed capacity to date is about 2,703.5MW. $50 \%$ of installed capacity comes from hydropower installations, with the rest coming from thermal plants burning Natural Gas (NG), Light Crude Oil (LCO), or diesel. The generating units are owned and operated primarily by the Volta River Authority (VRA); however, some Individual Power Producers (IPPs) have begun to enter the market [3].

The table below shows the mix of thermal generation assets and hydro generation assets in Ghana

Table 1: Installed Capacity in Ghana [3]

\begin{tabular}{|c|c|c|c|c|}
\hline Name & $\begin{array}{c}\text { Owner } \\
\text { Installed } \\
\text { Capacity } \\
\text { (MW) }\end{array}$ & $\begin{array}{c}\text { Reliable } \\
\text { Capacity } \\
(\text { MW) }\end{array}$ & Fuel \\
\hline Akosombo Dam & VRA & 1020 & 140 & Hydro \\
\hline Kpong Dam & VRA & 160 & 80 & Hydro \\
\hline Bui Dam & BPA & 260 & 80 & Hydro \\
\hline Aboadze T1 Thermal & VRA & 330 & 200 & NG \\
\hline Aboadze T2 (TICo) & IPP & 220 & 220 & NG \\
\hline Tema TT1PP & VRA & 126 & 110 & NG \\
\hline TEMA TT2PP & IPP & 49.5 & 45 & NG \\
\hline OSONOR (CENIT) & IPP & 126 & 120 & NG \\
\hline Tokaradi 3 & VRA & 132 & 120 & NG \\
\hline Tema Mine Reserve Plant & IPP & 80 & 40 & NG \\
\hline Sunon Asogli & IPP & 200 & 180 & NG \\
\hline Total & 11 & $2,700.5$ & 1,205 & \\
\hline
\end{tabular}

\subsection{Sub-Sectors}

The power sector in Ghana is divided into three major subsectors which are; Generation (VRA), Transmission (Gridco) and Distribution (ECG/NEDco).

\subsection{Ghana Grid Company Limited}

Ghana Grid Company Limited (GridCo) is an independent transmission system operator formed in accordance with the Energy Commission Act, 1997 (Act 541) [4] and the Volta River Development Act, 2005 (Act 692). GridCo was formed in December 2006, and took over VRA's transmission functions and assets in 2008. GridCo is responsible for the operation and maintenance (O\&M) of all transmission lines throughout Ghana. To carry out this responsibility Grid Co is also in charge of:

- Undertaking economic dispatch and transmission of electricity from wholesale suppliers (generating companies) to bulk customers and distribution companies

- Providing fair and non-discriminatory transmission services to all power market participants

- Providing metering and billing services to bulk customers

- Carrying out transmission system planning, investing to provide the capacity to reliably transmit electric energy, and managing the wholesale power market.

GridCo funds all of its operations through a transmission service charge levied on electricity delivered to distribution companies and through electricity sold directly to bulk customers. GridCo has successfully turned a profit the last three years. [5]

\subsection{Electricity Company of Ghana}

The Electricity Company of Ghana (ECG) is a limited liability company wholly owned by the Government of Ghana and operating under the Ministry of Power. Known as the Electricity Department when it was founded in 1947, it was converted into the Electricity Corporation of Ghana by Decree 125 in 1967 and incorporated under the Companies Code in February 1997 [6].

ECG is responsible for distributing electricity in the southern part of Ghana. This includes the Ashanti, Central, Eastern, Greater Accra, Volta, and Western regions. Within those regions, ECG has 1.8 million customers and distributes 90 percent of all electricity sold in Ghana. In 2013, ECG's customer base consisted of:

- Lifeline consumers that consume less than $50 \mathrm{kWh}$ per month-they represent 51 percent of ECG's customers, 6 percent of consumption, and 1 percent of sales revenue

- Non-residential consumers - these customers represent 12 percent of energy consumption and 56 percent of sales revenue

- Non-lifeline residential consumer-these consumers represent 34 percent of energy consumption and 36 percent of sales revenue

- Special Load Tariff and high-voltage mines-these customers represent 48 percent of consumption and seven percent of sales revenue.

- ECG has registered losses of US\$16 million in 2011, US\$44 million in 2012 and US\$60 million in 2013.[5]

\subsection{Northern electricity Distribution Company of Ghana}

NEDCo is a wholly owned subsidiary of VRA responsible for the distribution of electricity in the northern part of Ghana. NEDCo serves the Northern, Upper West, Upper East, Brong-Ahafo, Sunyani, and Techiman regions. In those regions, which have an average electrification rate of 36 percent, NEDCo has 420,000 customers. These regions represent about 64 percent of the landmass of Ghana, but 


\section{International Journal of Science and Research (IJSR) \\ ISSN (Online): 2319-7064}

Index Copernicus Value (2013): 6.14 | Impact Factor (2015): 6.391

only 10 percent of power demand, with a peak load of 120MW[7].

\subsection{Public Utilities Regulatory Commission}

The PURC is a fully independent body established under the Public Utilities Regulation Act (Act 538) responsible for regulating electricity and gas tariffs and enforcing customer service obligations of all public utilities. The PURC's regulatory responsibilities for public utilities are to:

- Provide guidelines on rates chargeable for utility services

- Examine and approve tariffs charged by public utilities

- Protect the interests of consumers and providers of public utility services

- Monitor the standard of performance of these utilities

- Receive and investigate complaints and settle disputes between consumers and public utility

- Promote fair competition among service providers in electricity, as well as in water.

Under the Energy Commission Act 1997 (Act 541), PURC is also required to approve charges for the supply, transmission, and distribution of electricity and $\mathrm{NG}$; as well as the bulk storage and transportation of petroleum products.[8]

\section{Current Electricity Situation}

Ghana is faced with many electricity problems which range from generation, transmission to distribution and marketing. We will review this problems one after the other;

\subsection{Generation}

The total installed capacity of the currently generating plants in Ghana as discussed earlier is 2,700.50 MW, but the available Capacity is less than 605.5 MW as at December 2013. Five out of the Eleven generation stations are over 20 years old and the average daily power generation is lower than the peak forecast for the current existing infrastructure. Through the planned generation capacity projects for a brighter future, the current status of power generation in Ghana presents challenges, such as inadequate generation availability, delayed maintenance of facilities, insufficient funding of power stations, obsolete equipment, tools, safety facilities and operational vehicles, obsolete communication equipment, lack of exploration to tap all sources of energy from the available resources and low staff morale [9] [10].

\subsection{Transmission}

Major problems associated with transmission systems include poor funding by the Central Government, it is yet to cover many parts of the country, it's current maximum electricity wheeling capacity is 1,205 MW which is awfully below the required national needs, some sections of the grid are outdated with inadequate redundancies as opposed to the required arrangement, regular vandalization of the lines, associated with low level of surveillance and security on all electrical infrastructure, technologies used generally deliver very poor voltage stability and profiles, there is a high prevalence of inadequate working tools and vehicles for operating and maintaining the network, there is a serious lack of required modern technologies for communication and monitoring, transformers deployed are overloaded in most service areas, inadequate of spare parts for urgent maintenance, poor technical staff recruitment, capacity building and training programme [9] [10].

\subsection{Distribution and Marketing}

In most regions in Ghana, the distribution network is poor, the voltage profile is poor and the billing is inaccurate. As the department, which inter-faces with the public, the need to ensure adequate network coverage and provision of quality power supply in addition to efficient marketing and customer service delivery cannot be over emphasized. Some challenges identified are, weak and inadequate network coverage, overloaded transformers and bad feeder pillars, substandard distribution lines, poor billing system, unwholesome practices by staff and very poor customer relations, inadequate logistic facilities such as tools working vehicles, poor and obsolete communication equipment, low staff morale and lack of regular training, insufficient funds for maintenance activities [9] [10].

\subsection{Power Deficit}

The total installed capacity of generating plants in Ghana plus the total installed capacity from the Independents Power Producers (IPP) is 2,700.5 MW with available capacity less than 1,495 MW, but power generation has been below 900 MW. Using the rule of Thumb, where $1000 \mathrm{MW}$ is for $1,000,000$ people and the Ghanaian population is approximately $27,000,000$ [11], we should have about 27,000 MW for the Ghanaian people but with the power generation that has not exceeded $900 \mathrm{MW}$, we can say that Ghana has a power deficit of 24,300 MW. Surprisingly, Ghana is still growing at anazing 6\% - 8\% [11] and the nation is doing so without almost no power (from the national grid) compared to other rapidly growing nations like South Africa with a population of about 50 million people and still generates over $45,000 \mathrm{MW}$ of electricity.

\section{Smart Grid Technology}

Various authors, government organization and bodies have given numerous definitions of smart grid. A smart grid can be defined as an upgraded electricity grid network enabling twoway information and power exchange between suppliers and consumers, due to the pervasive incorporation of intelligent communication monitoring and management systems [12]. The US Department of Energy (DOE) defined smart grid as a system that will incorporate digital technology to improve reliability, efficiency and security of the electric system [13]. According to the International Energy Agency Technology Roadmap Smart Grid; a smart grid is an electricity network that uses digital and other advance technologies to monitor and manage the transport of electricity from all generation sources to meet the varying electricity demand of end-users. The smart grid will organize various capabilities and needs of the grid operators, generations, end-users and electricity market stakeholders to operate all the parts of the system as 


\section{International Journal of Science and Research (IJSR) \\ ISSN (Online): 2319-7064}

Index Copernicus Value (2013): 6.14 | Impact Factor (2015): 6.391

efficiently as possible, reducing environmental impacts and cost while improving system reliability, resilience and stability [14]. Besides the smart grid being able to match supply with demand, it will also reduce the emission of greenhouse gases (GHG) by reducing the heavy dependence on fossil fuel plants through the integration of renewables which will make the system flexible and also electricity use will be more efficiently utilized.

\subsection{Wide Area Monitoring and Control}

Real-time monitoring and display of power system components and performance, across interconnections and over large geographic areas, help system operators to understand and optimize power system components, behavior and performance. Advanced system operation tools avoid blackouts and facilitate the integration of variable renewable energy resources. Monitoring and control technologies along with advanced system analytics-including wide area situational awareness (WASA), wide-area monitoring systems (WAMS), and wide-area adaptive protection, control and automation (WAAPCA)-generate data to inform decision making, mitigate wide area disturbances, and improve transmission capacity and reliability [14].

\subsection{Information Communication Technology Integration}

Underlying communications infrastructure, whether using private utility communication networks (radio networks, meter mesh networks) or public carriers and networks (Internet, cellular, cable or telephone), support data transmission for deferred and real-time operation, and during outages. Along with communication devices, significant computing, system control software and enterprise resource planning software support the two-way exchange of information between stakeholders, and enable more efficient use and management of the grid [14].

\subsection{Renewable and Distributed Generation}

Integration of renewable and distributed energy resources encompassing large scale at the transmission level, medium scale at the distribution level and small scale on commercial or residential building can present challenges for the dispatch ability and control ability of these resources and for operation of the electricity system. Energy storage systems, both electrically and for thermally based, can alleviate such problems by decoupling the production and delivery of energy. Smart grids can help through automation of control of generation and demand (in addition to other forms of demand response) to ensure balancing of supply and demand [14].

\subsection{Distribution Grid Management}

Distribution and sub-station sensing and automation can reduce outage and repair time, maintain voltage level and improve asset management. Advanced distribution automation processes real-time information from sensors and meters for fault location, automatic reconfiguration of feeders, voltage and reactive power optimization, or to control distributed generation. Sensor technologies can enable condition- and performance-based maintenance of network components, optimizing equipment performance and hence effective utilization of assets [14].

\subsection{Advance Metering Infrastructure}

Advanced metering infrastructure (AMI) involves the deployment of a number of technologies - in addition to advanced or smart meters that enable two-way flow of information, providing customers and utilities with data on electricity price and consumption, including the time and amount of electricity consumed. AMI will provide a wide range of functionalities which will include; Remote consumer price signals, ability to collect, store and report customer energy consumption data for any required time intervals or near real time, improved energy diagnostics from more detailed load profiles, ability to identify location and extent of outages remotely via a metering function that sends a signal when the meter goes out and when power is restored, remote connection and disconnection, losses and theft detection, ability for a retail energy service provider to manage its revenues through more effective cash collection and debt management [14].

\subsection{Customers-Side System}

Customer-side systems, which are used to help manage electricity consumption at the industrial, service and residential levels, include energy management systems, energy storage devices, smart appliances and distributed generation. Energy efficiency gains and peak demand reduction can be accelerated with in-home displays/ energy dashboards, smart appliances and local storage. Demand response includes both manual customer response and automated, price-responsive appliances and thermostats that are connected to an energy management system or controlled with a signal from the utility or system operator [14].

\section{Smart Grid Integration into The Ghanaian Grid Network}

It is important to note that some technologies have been employed in the Ghanaian grid system that can be upgraded to improve the "smartness" of the grid.

\subsection{Integration}

The following explains the various enhancements needed in order to fully integrate the smart grid network in the Ghana electricity grid system;

\subsection{Wide Area Monitoring and Control}

If sensory equipment like Phasor Measurement Units (PMU), strain gauge, infrared sensors, magnetic sensors and accelerometers are integrated into the Ghanaian grid system will ensure proper monitoring and enable the system to automatically adapt and respond to changing conditions. Also, distribution devices will become intelligent remote on communication networks providing data collected through sensors back to operations control centers. Current 


\section{International Journal of Science and Research (IJSR) \\ ISSN (Online): 2319-7064}

Index Copernicus Value (2013): 6.14 | Impact Factor (2015): 6.391

technology on the national grid does not monitor power flows throughout the distribution grid because measurements are usually only available at the distribution substations. The sensors will also be able to collect information. Other types of wide area monitoring and control equipment that can also be mounted as mentioned in Section 4 include: Advance system operator tools, wide area situation awareness (WASA), Wide Area Monitoring System (WAMS) and Wide Area Adaptive Protection, Control and Automation (WAAPCA). The defunct Power Holding Company of Nigeria (PHCN) introduced Supervisory Control and Data Acquisition Systems (SCADA) to its power system to enable data monitoring and data collection of the generating stations. Other useful software includes Grid LAB-D, Oracle Utilities Meter Data Management, Distribution Management System (DMS), and Visualizing Energy Resources Dynamically on Earth (VERDE) [15] [16].

\subsection{Storage Devices}

Energy storage devices like Hybrid Air Conditioning systems which come with lithium battery and inverter can convert electrical energy to thermal energy and store it. This is more economical than storing electricity in batteries. Such storage capabilities will be needed to grow the alternative energy sources, where unstable power flow from renewable energy plants such as wind and solar farms can be stored and better controlled. It can also supply power to the grid when it goes into island mode [14].

\subsection{Distributed Generation (Renewables and Micro-Grid)}

As previously discussed in this article, Ghana's electricity generating facilities are mainly thermal power plants and large centralized hydro plants scattered across the country. However, electricity must have to get to the users irrespective of where they reside. We also examined the renewable energy resources in Ghana, which is abundant in nature and yet not fully tapped. The integration of renewable energy into the national grid is one of the most important areas for infrastructure upgrades. Considering the high variability and unpredictability of generation from renewable energy sources, the power generated can be safely absorbed in the grid if the frequency is maintained in an appropriate range. Frequency Support Ancillary Service (FSAS) can be used to complement the daily changes in the renewable generation. In the future, based on the renewable forecast for the day, a dispatch schedule for FSAS can be prepared such that the variation in the renewable energy generation can be absorbed easily. In other words, FSAS can be used as a mechanism to facilitate renewable energy integration by reducing the impact of variable generation [17].

Micro-grids can be utilized as a framework of system that can reduce the negative effect of power fluctuation on existing power systems, simultaneously pursuing the coexistence of environmental and supply, and existing power system and distributed power generation. They can also be considered to be flexible load. It keeps the power demand and supply balance by connecting to the external power system for maintenance of frequency and voltage. Micro-grid operators buy power through tie-line from the utility company when power in the micro- grids is deficient, and sell power when the power generated is in excess [10] [18].

\subsection{Advanced Metering Infrastructure}

In the past, electromechanical meters were used by consumers of the defunct Power Holding Company of Ghana, they had mechanical parts that spin as electricity is consumed in the premises, and they show usage readout on small dials that a utility meter reader reads while on the property of your home. Presently in Ghana, prepaid meters have been introduced in an effort to provide more efficient service for electricity consumers whereby the buy prepaid cards according to what they can afford [10] [18]. The prepaid meter disconnects from the national grid network once the available credit on the card runs out due to the customer home use. Smart meters, otherwise referred to as Advanced Metering Infrastructure (AMI) or two-way meters are electric meters which utilize two-way communications between the meters and the utility company and enable two way power flows to consumers. This technology enables users to monitor their consumption patterns in real-time and enables features which include time stamping of meter data, outage reporting, communication into the customer premise and on-request reads. It also enables the consumer to supply power back to the grid from solar panels or other local renewable sources and enables load management by responding to fluctuations in demand [10] [18].

\subsection{Customers-Side System}

With the introduction of smart grid technologies in Ghana, customer-side system will also be introduced to aid in electricity management by residential, service and industrial customers, the include; smart appliances, energy storage devices, energy management devices and energy applications for smart phones and tablets.

\section{Factors That May Affect Smart Grid Integration in Ghana}

Smart grid is possible in Ghana as we have previously discussed, the next step is to identify the factors that may affects its integration in Ghana as follows;

\subsection{Vandalism of transmission lines and distribution equipment}

The vandalisation of the transmission infrastructures and the distribution equipment has been a common occurrence, even before the on-going power sector reforms. Most times, the sabotage is blamed on the power brokers who imports power generators. Vandalism is one of the current challenges that will likely translate hinder or cripple the integration of Smart grid in Ghana [2].

\subsection{Poor maintenance of existing power system}

Over the years of electricity infrastructures in Ghana, poor maintenance has been one of the major causes of epileptic nature of power supply, even when generation capacity rises 


\section{International Journal of Science and Research (IJSR) \\ ISSN (Online): 2319-7064}

Index Copernicus Value (2013): 6.14 | Impact Factor (2015): 6.391

and Smart grid is introduced; its utilization is limited by the malfunctioning of the transmission and distribution infrastructure. The only known maintenance carried out by the power sector workers is fault clearing while scheduled maintenance for healthy function and life extension of such infrastructure is non-existent [2].

\subsection{Low generating capacity}

The country's present overdependence on gas fired generation plants has resulted in supply disruptions in times of gas shortages which are very common occurrences. This, coupled with the high vulnerability of Ghana's electricity network system has so far contributed to the unreliability of the overall system. Commercial electricity generation in Ghana currently comes from power stations and various independent power projects around the country generating available electricity capacity of $6056 \mathrm{MW}$ which translates to 28 watts per capita power capacity. This is grossly inadequate even for domestic consumption. For Ghana to meet up its energy needs, it requires per capita power capacity of 1000 watts or power generating/handling capacity of 170,000 MW [19].

\subsection{Lack of institutional arrangement}

The lack of implementation of clean energy policies and the lack of coordination among relevant government agencies has created distortions and makes clean energy development more difficult. Inter-ministerial rivalries, overlap of mandates and outright protection of space often send wrong signals to potential investors. The absence of a clear political vision and leadership, weak regulatory institutions and inadequate human capacity, coupled with limited funding by government, all add up to make Ghana's renewable energy market look dwarfed compared to that of much smaller countries like Kenya. Currently, there is little hope for a quick transition to a green economy. No program to equip rural women with small-scale renewable energy education and knowledge. The proposed Climate Change Commission under the Presidency would have the potential to increase synergies across ministries, and government agencies at the federal, state and local levels. However, the Bill to establish the Commission remains unsigned by the President. All these will have negative effect on smart grid if the technology is to be introduced in Ghana [20].

\subsection{Corruption}

The menace of corruption has set the nation backward among her contemporaries. Corruption is a ubiquitous practice that has ravaged every sector of the economy in Ghana, including the power sector. Reform is not spared from its venom. The instances of corruptions in the power sector are numerous and provoking to even discuss about.

\subsection{Consumer behavior}

Due to the unreliable nature of power supply, consumers developed a poor power usage methodology. This method tends towards wasting energy instead of making proper use of it. For instance most consumers don't use energy saving bulbs and rarely switch off portions of energy that are not in use. The inclusion of smart metering will curtail these wastages because energy usage will become more interactive and cost effective, making people purchase what they really need.

\section{Benefits of Smart Grid Technology}

There are various ways Ghana and her citizens can benefit from the proposed integration of smart grid technology [14]:

- The smart grid will accommodate all generation and storage options. It will seamlessly integrate many types of electrical generation and storage systems with a simplified interconnection process analogous to "plug and play" technology of the retail computer industry

- Optimizes asset utilization and operating efficiency. A smart grid applies the latest technologies to optimize the use of its assets. For example, optimized capacity can be attainable with dynamic ratings, which allow assets to be used at greater loads by continuously sensing and rating their capacities.

- The smart grid will ensure the level of power quality desired by the users. New power quality standards will balance load sensitivity with delivered power quality at a reasonable price. The modernized grid will supply varying grades of power quality at different pricing levels. Not all commercial enterprises, and certainly not all residential customers, need the same quality of power. A smart grid supplies varying grades (and prices) of power.

- The grid will heal itself. The modernized grid will perform continuous self-assessments to detect, analyze, respond to and as needed, restore grid components or network sections. It will handle problems too large or too fast moving for human intervention. Acting as the grid's "immune system", self-healing will help maintain grid reliability, security, affordability, power quality and efficiency.

- The smart grid will resist attack. Security requires a systemwide solution that will reduce physical and cyber vulnerabilities and recovers rapidly from disruptions. Both its design and its operation will discourage attacks, minimize their consequences and speed service restoration. Resiliency refers to the ability of a system to react to unexpected events by isolating problematic elements while the rest of the system is restored to normal operation. These self-healing actions result in reduced interruption of service to consumers and help service providers better manage the delivery infrastructure.

- The modern grid will enable markets to flourish. Openaccess markets expose and shed inefficiencies. The modern grid will enable more market participation through increased transmission paths, aggregated demand response initiatives and the placement of energy resources including storage within a more reliable distribution system that is closer to the consumer. 


\section{International Journal of Science and Research (IJSR) \\ ISSN (Online): 2319-7064}

Index Copernicus Value (2013): 6.14 | Impact Factor (2015): 6.391

- It will motivate consumers to be an active grid participant and will include them in grid operations. In the modernized grid, well-informed consumers will modify consumption based on the balancing of their demands and the electric system's capability to meet those demands. Demand for new cost-saving and energy- saving products will benefit both the consumer and the power system. Consumers help balance supply and demand, and ensure reliability by modifying the way they use and purchase electricity. These modifications come as a result of consumers having choices that motivate different purchasing patterns and behavior. These choices involve new technologies, new information about their electricity use, and new forms of electricity pricing and incentives [14].

\section{Conclusion}

In this paper, we have observed that the Ghanaian electricity grid is faced with a lot of problems which include the insufficient and inefficient power generation facilities, inadequately maintained long transmission lines / and distribution facilities, and outdated metering system used by its customers. The integration of smart grid technology and renewables into the Ghanaian electricity grid system remains the only solution to the electricity crisis in the country. We have shown that the smart grid technology is possible in Ghana through the various technological integrations, enhancement and policy recommendation given in this paper. The benefits of the smart grid technology will not only improve electricity production and efficiency in Ghana, but will also enable electricity consumers to become producers of electricity and enhance Ghana's international competiveness. Limitation in this paper includes analysis like cost benefit analysis, Feed-in-Tariffs (FITs), Renewable Portfolio Standards (RPS), Renewable Energy Certificate (REC) which were not discussed in order to determine the best policy mechanism for renewable energy and smart grid integration in Ghana, therefore this limitation should be addressed in subsequent research.

\section{References}

[1] Sambo, A.S. (2009) Strategic Developments in Renewable Energy in Ghana. International Association for Energy Economics 16

[2] World bank Databank. http://www.tradingeconomics.com/nigeria/access-toelectricity-percent-of-population-wb -data

[3] Kunateh, M. "Gov't Cenpower Sign Agreement." The Chronicle, November 27, 2012 Accessed on January, 2015 at :http://thechronicle.com.gh/govt-cenpower-signagreement/

[4] "National Energy Policy." Ghanaian Ministry of Energy, Assessed in February, 2016.

[5] "Energizing Economic Growth: Making the Power and Petroleum Sectors Rise to the Challenge." World Bank, June 2013

[6] "About US." ECG Accessed on January , 2016 at: http://www.ecgonline.info/index.php/organisation/aboutus
[7] "About Us." NEDCo Accessed on March, 2016 at: http://www.nedco.com.gh/about_us.php

[8] "Public Utilities Regulatory Commission Act (Act 538)." Ghanaian Parliament, 1997

[9] Sambo, A.S., Garba, B., Zarma, I.H. and Gaji, M.M. (2003) Electricity Generation and the Present Challenges in the Nigerian Power Sector. Energy Resources Review, 4, 7-10.

[10] Patrick, O., Tolulolope, O. and Sunny, O. (2013) Smart Grid Technology and Its Possible Applications to the Nigeria 330 kV Power System. Smart Grid \& Renewable Energy, 4, 391.

[11] Ghanaian Population http://www.cia.gov/library/publications/the-worldfactbook/geos/gh

[12] Giordano, V. and Bossart, S. (2012) Accessing Smart Grid Benefits and Impacts: EU and U.S Initiatives.

[13] U.S. Department of Energy (DOE) (2009) The Modern Grid System, A Vision for the Smart Grid. National Energy Technology Laboratory

[14]IEA (2011) Technology Road Map on Smart Grids. International Energy Agency

[15](2009) Oracle White Paper: Smart Grids-Strategic Planning and Development.

[16] Smart Grid by PDHengineer.com, Course No. E-5006. http://www.pdhengineer.com/page-not-found-404

[17](2013) Integrating Wind and Solar Energy in India for a Smart Grid Platform, Global Energy Network Institute (GENI).

[18](2009) Integration of Demand-Side Management, Distributed Generation, "Renewable Energy Sources and Energy Storages", International Energy Agency Demand-Side Management Programme (Ieadsm), Finland.

[19] Aniefiok, E., Igweonu, I.E., Eguzo, C.V. and Robert, B.J. (2013) Integrating Smart Grid Model in Nigeria Power Network. International Journal of Advances in Engineering \& Technology, 6, 1760-1768.

[20] Mshelia, I.H. (2012) Energy Access for All: The Role of Clean Energy in Alleviating Energy Poverty. http://us.boell.org/2012/05/18/green-deal-nigeriagreening-economy 